\title{
Onset of Time of Ischaemic Stroke among Elderly Patients in Bangladesh
}

\author{
KAZI JANNAT ARA ${ }^{1}$, ROFIQUL ISLAM ${ }^{1}$, AHSAN HABIB ${ }^{1}$, ANIS AHMED ${ }^{1}$, \\ HAFIZUR RAHMAN ${ }^{1}$, NILUFAR FATEMA ${ }^{2}$
}

${ }^{1}$ Department of Neurology, Bangabandhu Sheikh Mujib Medical University (BSMMU), Shahbag, Dhaka, ${ }^{2}$ Department of Cardiology, Bangabandhu Sheikh Mujib Medical University (BSMMU), Dhaka.

Address for Correspondence: Dr Kazi Jannat Ara, Medical Officer, Department of Neurology, Bangabandhu Sheikh Mujib

Medical University (BSMMU), Shahbag, Dhaka. E mail: rimmineuro@gmail.com

\begin{abstract}
:
Stroke is ranked as the third leading cause of death in Bangladesh. According to the World Health Organization, mortality rate of Bangladeshi population due to stroke as number 84 in the world. The reported prevalence of stroke in Bangladesh is $0.3 \%$, although no data on stroke incidence have been recorded. There is no well-documented data of the time of onset of ischaemic stroke. This study was done to find out timing and relationship with activity among elderly ischaemic stroke patients. This cross sectional study was conducted in Out Patient department (OPD) stroke clinic and Indoor of the department of neurology, BSMMU, Dhaka from July 2015 to June 2016. A total 200 patients suffering from ischaemic stroke within the range of 61-95 years of age of both sexes were included. Patient with TIA, hemorrhagic stroke and stoke after one month of onset were excluded. Male and female ratio was 1.95:1. Mean age was $68.4 \pm 8.24$ years. clinical presentation of the patients. Hemiparesis was presented in $66.2 \%$ patients followed by $57.0 \%$ patients were inability to talk, $33.8 \%$ presented with hemiplegia, $20.4 \%$ had vertigo, 9.2\% had headache, $7.0 \%$ had vomiting, $2.8 \%$ had loss of consciousness and $2.1 \%$ had convulsion. Maximum incidences were occurred during sleep (36.6\%), during day to day activity $39.4 \%$ and resting condition $(21.8 \%)$ respectively.
\end{abstract}

University Heart Journal 2018; 14(1): 28-30

Introduction:

Ischaemic stroke, myocardial infarction and sudden death occur most often after awakening in the morning hours. In a metaanalysis of 31 publications showed the timing of 11,816 strokes found a $49 \%$ increase in stroke of all types between 6 am and 12 noon. ${ }^{1}$ The circadian pattern of transient ischaemic attack remains unknown. Possible explanations for the circadian pattern of cerebrovascular events have focused on circadian or postural changes in platelet aggregation, thrombolysis, blood pressure, heart rate, and catecholamine concentrations. Then it occurs after awakening with of physical and mental activities. In a minority of cases, which varies in the literature from less than $10 \%$ to as much as $44 \%$, stroke occurs at night. ${ }^{2-4}$ Although the sleep is thought to be protective for most cerebrovascular events, may represent a vulnerable state for a group of patients at risk for stroke. Nocturnal blood pressure swings, cardiac arrhythmias, and sleep disordered breathing have been suggested as possible explanations for the nocturnal onset of stroke. Most of the people of Bangladesh are not concerned about the risk factors, warning signs and onset of time of stroke. In the absence data about time onset of ischaemic cerebrovascular events in elderly this study was performed to analysis of time onset of ischaemic stroke.

\section{Methodology:}

This cross sectional study was conducted in outpatient department (OPD), Stroke Clinic and Indoor of the Department of Neurology, BSMMU, Dhaka, from June 2015 to June 2016. 142 patients suffering from Ischaemic stroke of age more than 60 years of both sexes were included according to inclusion and exclusion criteria and gave informed written consent from the patients or guardians after full explanation of the purpose of the study.

Inclusion criteria:

1. Clinically diagnosed as Ischaemic stroke of both sexes and age more than 60 years 
2. Confirmed by CT / MRI scan within one month of stroke

\section{Exclusion criteria:}

1. Patient with transient ischaemic attack.

2. Patient with hemorrhagic stroke of any duration,

3. Stroke after one month of onset.

4. Ischemic stroke due to valvular atrial fibrillation (AF), prosthetic heart valve, infective endocarditis, patent foramen ovalae, atrial septal defect and atrial myxoma.

Clinical diagnosis was established from history and thorough physical examination. All data were recorded systematically in preformed data collection form (questionnaire). Computer based statistical analysis were carried out with appropriate techniques and systems. Continuous data were expressed as mean and standard deviation and qualitative data were expressed as frequency distribution and percentage. Statistical analysis was performed by using window based computer software devised with Statistical Packages for Social Sciences (SPSS-20) (SPSS Inc, Chicago, IL, USA). Associations between qualitative data were analyzed by chi-square test. For all statistical tests, we considered $p$ value $<0.05$ as statistically significant.

\section{Results:}

Table-I

Distribution of patients by gender $(n=142)$

\begin{tabular}{lcc}
\hline Gender & Frequency & Percentage $\%$ \\
\hline Male & 94 & 66.2 \\
Female & 48 & 33.8 \\
Total & 142 & 100 \\
\hline
\end{tabular}

Table I shows male was predominant than female. Male female ratio was $1.95: 1$.

Table-II

Distribution of patients by age group

\begin{tabular}{lcc}
\hline Age group & Frequency & Percentage \\
\hline $61-70$ & 101 & 71.1 \\
$71-80$ & 27 & 19.0 \\
$>80$ & 14 & 9.9 \\
Total & 142 & 100.0 \\
Mean \pm SD & $68.4 \pm 8.24$ & \\
Range (min-max) & $61-95$ & \\
\hline
\end{tabular}

Table II shows distribution of patients according to age. Maximum patients were in age group 61-70 years in both groups. Mean age was $68.4 \pm 8.24$ years within the range of $61-95$ years.

Table-III

Distribution of the patients by clinical presentation

\begin{tabular}{lcc}
\hline Clinical presentation & Frequency & Percentage \\
\hline Hemiparesis & 94 & 66.2 \\
Inability to talk & 81 & 57.0 \\
Hemiplegia & 48 & 33.8 \\
Vertigo & 29 & 20.4 \\
Headache & 13 & 9.2 \\
Vomiting & 10 & 7.0 \\
Loss of consciousness & 4 & 2.8 \\
Convulsion & 3 & 2.1 \\
\hline
\end{tabular}

Table III shows clinical presentation of the patients. Hemiparesis was presented in $66.2 \%$ patients followed by $57.0 \%$ patients were inability to talk, $33.8 \%$ presented with hemiplegia, $20.4 \%$ had vertigo, $9.2 \%$ had headache, $7.0 \%$ had vomiting, $2.8 \%$ had loss of consciousness and $2.1 \%$ had convulsion

Table IV

Distribution of patients by time of onset

\begin{tabular}{lcc}
\hline Time of onset & Frequency & Percentage \\
\hline During sleeping & 52 & 36.6 \\
Resting condition & 31 & 21.8 \\
During day to day activity & 56 & 39.4 \\
Strenuous exercise & 3 & 2.1 \\
\hline
\end{tabular}

Table IV: shows distribution of patients according to time onset. Maximum incidences were occurred during sleep (36.6\%), during day to day activity $39.4 \%$ and resting condition $(21.8 \%)$ respectively but Minimum in strenuous exercise about $2.1 \%$.

\section{Discussion:}

Stroke is a alarming health hazard all over the world and one of the leading causes of Morbidity, disability and mortality in developed as well as developing countries. In this study, male were predominant than female which were $94(66.2 \%)$ cases and 48 (33.8\%) cases respectively. Ischaemic stroke is more prevalent in men than in women. ${ }^{5}$ Similar result was found in the two studies. ${ }^{6,7}$ Stroke incidence rates are 1.25 times greater in men. Men develop ischemic strokes at higher rates than women up to the age of 75 years. Age is the single most important risk factor for stroke. For each successive 10 years after age 55, the stroke rate more 
than doubles in both men and women. ${ }^{8,9}$ In this study, mean age was $68.4 \pm 8.24$ years. Maximum patients were in age group 61-70 years. This result is consistent with the result of Sagui et al. and Zhang et al. Ischemic stroke is associated with aging. Regarding clinical presentation, hemiparesis presented in $66.2 \%$ patients followed by $57.0 \%$ patients were inability to talk, $33.8 \%$ presented with hemiplegia, $20.4 \%$ had vertigo, $9.2 \%$ had heacache, $7.0 \%$ had vomiting, $2.8 \%$ had loss of consciousness and $2.1 \%$ had convulsion. In this study, maximum incidences were occurred during sleep (36.6\%) or resting condition $(21.8 \%)$. Stroke during sleep was documented in 264 cases (18.2\%) in the study of Spengos et al. ${ }^{10}$ In a study, it has been found that low diastolic blood pressure values may predispose to night time onset of cerebrovascular events enhancing the sleep related fall in blood pressure. ${ }^{11}$ Another studies suggested a relation between night time hypotension and silent stroke ${ }^{12}$ and recurrent stroke. ${ }^{13}$ Further more study is needed to find out the cause of onset of ischaemic heart disease during sleep.

\section{Conclusion:}

Male suffers more than female from the ischaemic stroke in elderly. Most of the stroke cases occur in age group $61-70$ years among elderly peoples. Elderly are more prone to develop ischaemic stroke in during sleep and activity.

\section{References}

1. Elliott WJ. Circadian variation in the timing of stroke onset: a metaanalysis. Stroke 1998;29:992-6.
2. Marshall J. Diurnal variation in occurence of strokes. Stroke 1977;8:230-1.

3. van der Windt C, van Gijn J. Cerebral infarctions do not occur typically at night. J Neurol Neurosurg Psychiatry 1988; 51:109-11.

4. Cham orro A, Vila N, Ascaso C, et al. Blood pressure and functional recovery in acute ischemic stroke. Stroke 1998;29:1850-3.

5. Dey, S.K., Ahmed, S., Rahman, K.M., Uddin, M.J., Alam, M.R., Bhattacharjee, M., et al. 2010. Lipid profile among ischemic and haemorrhagic stroke patients. Mymensingh medical journal: MMJ, 19(2), 176-180.

6. Sagui, E., M'Baye, P.S., Dubecq, C., Fall, K.B., Niang, A., Gning, S., et al. 2005. Ischemic and Hemorrhagic Strokes in Dakar, Senegal. Stroke, 36(9), 1844-47.

7. Zhang, Y., Galloway, J.M., Welty, T.K., Wiebers, D.O., Whisnant, J.P., Devereux, R.B., et al. 2008. Incidence and risk factors for stroke in American Indians. Circulation, 118(15), 1577-84.

8. Brown, R.D., Whisnant, J.P., Sicks, R.D., O’Fallon, W.M., Wiebers, D.O., 1996. Stroke incidence, prevalence, and survival: secular trends in Rochester, Minnesota, through 1989. Stroke. 27, 373-80.

9. Wolf PA, D’Agostino RB, O’Neal MA, Sytkowski P, Kase CS, Belanger AJ, Kannel WB. Secular trends in stroke incidence and mortality: the Framingham Study.1992;23:1551-55

10. Spengos, K., Tsivgoulis, G., Manios, E., Synetou, M., Vassilopoulou, S., Zakopoulos, N., et al. 2005. Stroke etiology is associated with symptom onset during sleep. Sleep, 28(2), 233-38.

11. Millar-Craig MW, Bishop CN, Raftery EB. Circadian variation of blood pressure. Lancet 1978;1:795-7.

12. Watanabe N, Imai $Y$, Nagai $K$, et al. Nocturnal blood pressure and silent cerebrovascular lesions in elderly Japanese. Stroke 1996;27:1319-27.

13. Nakamura K, Oita J, Yamaguchi T. Nocturnal blood pressure dip in stroke survivors. A pilot study. Stroke 1995; 26:1373-8. 